P-ISSN 2580 - 7781

E-ISSN 2615 - 3238

\title{
PENGARUH KOMUNIKASI, INSENTIF DAN ETOS KERJA TERHADAP \\ PRESTASI KERJA APARATUR SIPIL NEGARA (ASN) DI KANTOR BAPPEDA KABUPATEN SITUBONDO
}

\author{
THE EFFECT OF COMMUNICATION, INCENTIVES AND WORK ETHOS \\ ON THE WORK ACHIEVEMENT OF STATE CIVIL APPARATUS (ASN) AT \\ THE BAPPEDA OFFICE OF SITUBONDO REGENCY
}

\author{
Mohammad Yahya Arief ${ }^{1)}$, Herfi Aj'wa Rhamdani ${ }^{2)}$ \\ ${ }^{1,2}$ Program Studi Manajemen, Fakultas Ekonomi \\ Universitas Abdurachman Saleh Situbondo \\ 1email : yarief106@gmail.com
}

\begin{abstract}
ABSTRAK
Tujuan penelitian ini yaitu untuk mengetahui pengaruh variabel komunikasi, insentif dan etos kerja terhadap prestasi kerja Aparatur Sipil Negara (ASN) di Kantor BAPPEDA Kabupaten Situbondo. Metode yang digunakan dalam penelitian ini adalah analisis regresi linier berganda, uji t, uji F, uji dominan dan koefisien determinasi. Berdasarkan hasil penelitian bahwa hasil regresi linier berganda $\mathrm{Y}=8,370 \mathrm{E}-17-0,669 \mathrm{X}_{1}+0,771 \mathrm{X}_{2}+0,472 \mathrm{X}_{3}+e$. Berdasarkan uji $\mathrm{t}$ variabel komunikasi dan insentif berpengaruh secara parsial terhadap prestasi kerja. Sementara etos kerja tidak berpengaruh secara parsial terhadap Prestasi kerja di BAPPEDA Kabupaten Situbondo. Hasil uji F variabel komunikasi, insentif dan etos kerja berpengaruh secara simultan terhadap prestasi kerja. Berdasarkan uji dominan variabel Insentif berpengaruh dominan terhadap Prestasi kerja di BAPPEDA Kabupaten Situbondo. Seluruh variabel bebas (Komunikasi, Insentif dan Etos kerja) mempunyai kontribusi sebesar 56,6\% terhadap variabel terikat (Prestasi kerja) dengan berpengaruh kuat, dan sisanya sebesar 43,4\% dipengruhi oleh variabel lain yang tidak masuk dalam penelitian
\end{abstract}

Kata kunci: Komunikasi, Insentif, Etos kerja, Prestasi kerja

\section{ABSTRACT}

The purpose of this study is to determine the effect of communication variables, incentives and work ethic on the work performance of the State Civil Apparatus (ASN) at the BAPPEDA Office of Situbondo Regency. The method used in this research is multiple linear regression analysis, $t$ test, $F$ test, dominant test and coefficient of determination. Based on the results of the study that the results of multiple linear regression $Y=8.370 E-17-0.669 X 1+0.771 X 2+0.472 X 3+e$. Based on the t-test, the communication and incentive variables have a partial effect on work performance. Meanwhile, work ethic has no partial effect on work performance at BAPPEDA Situbondo Regency. The results of the F test of communication, incentives and work ethic variables have a simultaneous effect on work performance. Based on the dominant test, the Incentive variable has a dominant effect on work performance at BAPPEDA Situbondo Regency. All independent variables (Communication, Incentives and work ethic) contributed 
P-ISSN $2580-7781$

E-ISSN 2615 - 3238

$56.6 \%$ to the dependent variable (work achievement) with a strong influence, and the remaining $43.4 \%$ was influenced by other variables not included in the study. Keywords: Communication; incentive; work ethic, work performance

\section{PENDAHULUAN}

Dalam rangka mencapai tujuan organisasi diperlukan suatu komunikasi yang baik antara pimpinan dengan pegawai, maupun antara pegawai dengan sesama rekan kerja. Diantara kelompok, untuk mencapai tujuan suatu organisasi. Kerja sama tersebut terdiri dari berbagai maksud yang meliputi hubungan sosial/kebudayaan. Hubungan yang terjadi merupakan suatu proses adanya suatu keinginan masing-masing individu, untuk memperoleh suatu hasil yang nyata dan dapat memberikan manfaat untuk kehidupan yang berkelanjutan. Handoko (2012) menyatakan bahwa komunikasi yaitu suatu proses dengan mana orang-orang bermaksud memberikan pengertian-pengertian melalui pengiriman berita secara simbolis, dapat menghubungkan para anggota berbagai satuan organisasi yang berbeda dan bidang yang berbeda pula sehingga sering disebut rantai pertukaran informasi.

Demi tercapainya tujuan suatu organisasi, maka pimpinan organisasi hendaknya bisa memberikan insentif karena daya kerja dan kesadaran individu dapat dirangsang melalui insentif. Pemberian insentif pun semata-mata bukan hanya dimaksudkan untuk menyenangkan pegawai, melainkan dengan insentif itu, kesadaran mereka untuk berprestasi diharapkan tumbuh. Yani (2012) mengatakan bahwa insentif penghargaan dalam bentuk uang yang diberikan oleh suatu organisasi atau perusahaan kepada karyawannya atas dasar prestasi kerja yang tinggi atau pada karyawannya yang bekerja melampaui standar yang telah ditentukan. Sebaiknya perusahaan dapat mempertahankan insentif untuk karyawan berprestasi karena dengan itu dapat memotivasi pegawai agar bekerja dengan efektif dan efisien agar terwujudnya produktivitas kerja pegawai yang unggul.

Begitu juga dengan etos kerja dikatakan sebagai faktor penentu dan keberhasilan individu, kelompok, institusi dan juga yang terluas ialah bangsa dalam mencapai tujuannya. Pada pelaksanaan administrasi publik juga dipengaruhi oleh etos kerja yang dimiliki oleh pejabat-pejabat publik dalam 
P-ISSN 2580 - 7781

E-ISSN 2615 - 3238

tugasnya menyelenggarakan kebutuhan masyarakat. Sinamo (2011), berpendapat bahwa etos kerja dapat diartikan sebagai konsep tentang kerja atau paradigma kerja yang diyakini oleh seseorang atau sekelompok orang sebagai baik dan benar yang diwujudnyatakan melalui perilaku kerja mereka secara khas.

Pada dasarnya setiap pegawai ingin mendapatkan penghargaan dari pimpinannya, maka untuk mendapatkan penghargaan itu setiap pegawai haruslah memiliki prestasi kerja yang tinggi. Hasibuan (2016) mengatakan bahwa prestasi kerja adalah suatu hasil kerja yang dicapai seseorang dalam melaksanakan tugastugas yang dibebankan kepadanya yang didasarkan atas kecakapan, pengalaman dan kesungguhan serta waktu.

Badan Perencanaan Pembangunan Daerah (BAPPEDA) merupakan lembaga strategis daerah, karena lembaga ini merupakan satu-satunya lembaga perencanaan yang ada di setiap daerah. Segala aktifitas perencanaan pembangunan di daerah dirancang lembaga ini. Disamping sebagai lembaga perencana, BAPPEDA juga berperan sebagai lembaga pengendali terutama pengendalian terhadap kesesuaian program/kegiatan yang direncanakan dengan yang dilaksanakan.

BAPPEDA Kabupaten Situbondo dibentuk berdasarkan Peraturan Daerah Kabupaten Situbondo Nomor 23 Tahun 2001 tentang Pembentukan Lembaga Teknis Daerah. BAPPEDA merupakan lembaga teknis daerah yang ada di Kabupaten Situbondo yang berkedudukan sebagai unsur pendukung Pemerintah Daerah dalam penyelenggaraan unsur pemerintahan dan pembangunan yang menjadi urusan rumah tangga daerah. BAPPEDA dipimpin oleh seorang Kepala Daerah melalui Sekretaris Daerah. Susunan organisasi BAPPEDA Kabupaten Situbondo ditetapkan dengan Peraturan Bupati Situbondo Nomor 48 Tahun 2011 Tentang Uraian Tugas dan Fungsi Badan Perencanaan Pembangunan Daerah (BAPPEDA) Kabupaten Situbondo.

Fenomena Komunikasi pada kantor Badan Perencanaan Pembangunan Daerah (BAPPEDA) Kabupaten Situbondo, dimana komunikasi yang kurang kondusif, permasalahan utama yaitu hubungan kerja antar sesama pegawai dan hubungan kerja antara bawahan dan atasan masih kurang efektif karena kurangnya komunikasi. Akibat dari permasalahan tersebut dapat berpengaruh terhadap 
P-ISSN $2580-7781$

E-ISSN 2615 - 3238

prestasi kerja ASN dan juga dapat menghambat kelancaran kinerja pegawai dalam menjalankan tugasnya. Hal ini tentu saja harus diperhatikan oleh pihak BAPPEDA agar dapat memberikan solusi dalam mengatasi permasalahan yang ada dan pegawai bisa bekerja dengan baik. Sehingga dapat meningkatkan prestasi kerja dan kinerja dalam menjalankan pekerjaannya. Komunikasi pada suatu perusahaan atau organisasi sangat penting untuk diperhatikan, sehingga disetiap instansi tidak terjadi lagi permasalahan seperti miskomunikasi antar sesama pegawai.

Penelitian ini mengambil objek penelitian pada kantor BAPPEDA Kabupaten Situbondo, salah satu kantor yang berlokasi di Jalan Moch. Seruji No. 3, Kabupaten Situbondo, Jawa Timur 68312. BAPPEDA khususnya di Kabupaten Situbondo selalu berupaya untuk meningkatkan prestasi kerja ASN. Prestasi kerja mereka dipantau secara berkala, mengingat peran yang cukup strategis dari prestasi kerja ASN terhadap kelangsungan hidup organisasi. Berdasarkan latar belakang di atas, membuat peneliti tertarik untuk melakukan penelitian berjudul "Pengaruh Komunikasi, Insentif dan Etos Kerja terhadap Prestasi Kerja Aparatur Sipil Negara (ASN) di Kantor BAPPEDA Kabupaten Situbondo".

Tujuan yang ingin dicapai dengan diadakannya penelitian ini adalah sebagai berikut:

1. Untuk mengetahui pengaruh Variabel Komunikasi, Insentif dan Etos kerja berpengaruh secara parsial terhadap Variabel Prestasi kerja Aparatur Sipil Negara (ASN) di Kantor BAPPEDA Kabupaten Situbondo.

2. Untuk mengetahui Variabel Komunikasi, Insentif dan Etos kerja berpengaruh secara simultan terhadap Variabel Prestasi kerja Aparatur Sipil Negara (ASN) di Kantor BAPPEDA Kabupaten Situbondo.

3. Untuk mengetahui diantara Variabel Komunikasi, Insentif dan Etos kerja yang berpengaruh dominan terhadap Variabel Prestasi kerja Aparatur Sipil Negara (ASN) di Kantor BAPPEDA Kabupaten Situbondo. 
P-ISSN 2580 - 7781

E-ISSN 2615 - 3238

\section{METODE PENELITIAN}

Penelitian ini dilakukan di Kantor BAPPEDA Kabupaten Situbondo yang berlokasi di Jl. Moch. Seruji No. 3 Situbondo. Populasi penelitian ini adalah ASN di Kantor BAPPEDA ada 41 orang. Sampel yang dipilih adalah ASN yang masih aktif pada tahun 2020/2021 adalah sebanyak 40 ASN. Variabel penelitian bebasnya yaitu komunikasi $\left(\mathrm{X}_{1}\right)$, insentif $\left(\mathrm{X}_{2}\right)$, etos kerja $\left(\mathrm{X}_{3}\right)$ dan variabel terikatnya prestasi kerja (Y). Data dikumpulkan melalui observasi, wawancara, kuesioner, studi pustaka, dan dokumentasi. Data dianalisis menggunakan regesi linear berganda.

\section{HASIL PENELITIAN DAN PEMBAHASAN}

Berdasarkan data penelitian yang dikumpulkan baik untuk variabel terikat (Y) maupun variabel bebas $\left(\mathrm{X}_{1}, \mathrm{X}_{2}\right.$ dan $\left.\mathrm{X}_{3}\right)$ yang diolah menggunakan bantuan program SPSS 22 for Windows, maka diperoleh hasil perhitungan regresi linier berganda sebagai berikut:

Tabel 1. Rekapitulasi Hasil Analisa Regresi Linier Berganda

\begin{tabular}{cccc}
\hline Model & B & t hitung & Sig \\
\hline Constant & 8.370 & 0.000 & 1.000 \\
Komunikasi & -0.669 & -2.043 & 0.048 \\
Insentif & 0.771 & 6.772 & 0.000 \\
Etos Kerja & 0.472 & 1.455 & 0.154 \\
\hline
\end{tabular}

Berdasarkan Tabel 1 dapat diperoleh persamaan regresi linier berganda

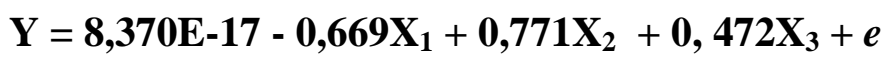

\section{Uji Statistik Parsial (t-test)}

Pengujian ini untuk melihat sejauh mana pengaruh secara parsial (sendirisendiri) variabel $\mathrm{X}$ (komunikasi, insentif dan etos kerja) terhadap variabel $\mathrm{Y}$ (Prestasi kerja).

1. Komunikasi $\left(\mathrm{X}_{1}\right)$

Nilai $t_{\text {hitung }}$ untuk variabel Komunikasi sebesar -2,043. Sementara itu nilai

pada $t_{\text {tabel }}$ distribusi 5\% sebesar 2,028 maka $t_{\text {hitung }}-2,043<t_{\text {tabel }}-2,028$ berarti $\mathrm{H}_{\mathrm{o}}$ ditolak dan $\mathrm{Ha}$ diterima. Hasil tersebut menunjukkan bahwa variabel komunikasi mempunyai pengaruh negatif signifikan terhadap Prestasi kerja. 
P-ISSN 2580 - 7781

E-ISSN 2615 - 3238

Hal ini juga diperkuat dengan nilai signifikan t 0,048 $<0,05$ artinya variabel Komunikasi berpengaruh secara parsial terhadap Prestasi kerja di BAPPEDA Kabupaten Situbondo.

2. Insentif $\left(\mathrm{X}_{2}\right)$

Nilai $t_{\text {hitung }}$ untuk variabel Insentif sebesar 6,772. Sementara itu nilai pada $t_{\text {tabel }}$ distribusi 5\% sebesar 2,028 maka $\mathrm{t}_{\text {hitung }} 6,772>\mathrm{t}_{\text {tabel }} 2,028$ berarti $\mathrm{H}_{\mathrm{o}}$ ditolak dan Ha diterima. Hasil tersebut menunjukkan bahwa variabel Insentif mempunyai pengaruh signifikan terhadap Prestasi kerja. Hal ini juga diperkuat dengan nilai signifikan t 0,000 $<0,05$ artinya variabel Insentif berpengaruh secara parsial terhadap Prestasi kerja di BAPPEDA Kabupaten Situbondo.

3. Etos kerja $\left(\mathrm{X}_{3}\right)$

Nilai $t_{\text {hitung }}$ untuk variabel Etos kerja sebesar 1,455. Sementara itu nilai pada $\mathrm{t}_{\text {tabel }}$ distribusi 5\% sebesar 2,028 maka $\mathrm{t}_{\text {hitung }} 1,455<\mathrm{t}_{\text {tabel }} 2,028$ berarti $\mathrm{H}_{\mathrm{o}}$ diterima dan Ha ditolak. Hasil tersebut menunjukkan bahwa variabel Etos Kerja tidak mempunyai pengaruh signifikan terhadap Prestasi kerja. Hal ini juga diperkuat dengan nilai signifikan 0,154>0,05 artinya variabel Etos Kerja tidak berpengaruh secara parsial terhadap Prestasi kerja di BAPPEDA Kabupaten Situbondo.

\section{Uji Statistik Simultan (F-test)}

Uji simultan atau uji F merupakan uji secara bersama-sama untuk menguji pengaruh signifikan variabel komunikasi, insentif, dan etos kerja berpengaruh secara simultan terhadap Prestasi kerja. Berdasarkan hasil pengolahan dengan menggunakan SPSS versi 22 for Windows maka didapat hasil uji F yang hasilnya dirangkum pada Tabel 2 berikut ini:

Tabel 2. Hasil uji simultan (Uji F)

\begin{tabular}{ccc}
\hline F Hitung & F Tabel & Sig \\
\hline 15,628 & 2,87 & 0.000 \\
\hline
\end{tabular}


P-ISSN 2580 - 7781

E-ISSN 2615 - 3238

Pengujian statistik dengan menggunakan metode uji $\mathrm{F}$, dimana nilai $\mathrm{F}_{\text {hitung }}$ $15,628>\mathrm{F}_{\text {tabel }} 2,87$ dengan tingkat signifikan yang diperoleh $0,000<0,05$, maka dapat disimpulkan bahwa hipotesis penelitian $\left(\mathrm{H}_{2}\right)$ yang menyebutkan bahwa terdapat pengaruh variabel komunikasi, insentif dan etos kerja berpengaruh secara simultan terhadap Prestasi kerja di BAPPEDA Kabupaten Situbondo.

\section{Uji Dominan}

Pengujian hipotesis variabel bebas (Komunikasi, Insentif dan Etos kerja) yang paling berpengaruh dominan terhadap Prestasi kerja ASN di BAPPEDA Kabupaten Situbondo menunjukkan nilai variabel bebas terhadap variabel terikat, dengan nilai $t_{\text {hitung }}$ untuk variabel Komunikasi $\left(\mathrm{X}_{1}\right)$ sebesar -2,043, Insentif $\left(\mathrm{X}_{2}\right)$ sebesar 6,772 dan Etos kerja $\left(\mathrm{X}_{3}\right)$ sebesar 1,455, maka kesimpulannya adalah nilai dari variabel Insentif tersebut lebih besar dari kedua variabel bebas yang lain yaitu sebesar 6,772 dengan demikian, hipotesis penelitian $\left(\mathrm{H}_{3}\right)$ yang menyatakan bahwa variabel Insentif berpengaruh dominan terhadap Prestasi kerja di BAPPEDA Kabupaten Situbondo dapat diterima.

\section{Pengaruh Komunikasi terhadap Prestasi kerja}

Hasil analisis menunjukkan bahwa variabel Komunikasi berpengaruh signifikan terhadap Prestasi kerja. Berdasarkan pengujian tersebut maka dapat disimpulkan bahwa hipotesis $\left(\mathrm{H}_{1}\right)$ yang menyatakan bahwa variabel Komunikasi berpengaruh secara parsial terhadap Prestasi kerja ASN di BAPPEDA Kabupaten Situbondo adalah diterima. Dan berdasarkan pengujian tersebut maka dapat disimpulkan bahwa hipotesis $\left(\mathrm{H}_{2}\right)$ yang menyatakan bahwa variabel Komunikasi berpengaruh secara simultan terhadap Prestasi kerja ASN di BAPPEDA Kabupaten Situbondo adalah diterima.

Argumen logis dan rasional terhadap diterimanya hipotesis pertama tersebut adalah terkait dengan Komunikasi yang terbentuk dari perusahaan. Hasil penelitian ini sesuai dengan pernyataan Feriyanto dan Endang (2015) mengemukakan bahwa "Komunikasi tidak hanya penting untuk manusia tetapi juga penting untuk sistem pengendalian manajemen yang merupakan alat untuk mengarahkan, memotivasi, memonitor atau mengamati, serta evaluasi 
P-ISSN $2580-7781$

E-ISSN 2615 - 3238

pelaksanaan manajemen perusahaan yang mencoba mengarahkan pada tujuan organisasi dalam perusahaan". Hal itu dimaksud agar kinerja yang dilakukan oleh pihak manajemen perusahaan dapat berjalan lebih efektif dan lancar.

Hasil penelitian ini sejalan dengan hasil penelitian yang dilakukan oleh Anni Karmila Nasution (2018) "Pengaruh Komunikasi dan Persepsi Lingkungan Kerja terhadap Prestasi Kerja Karyawan pada PDAM Tirtanadi Sumatera Utara Cabang Cemara".

\section{Pengaruh Insentif terhadap Prestasi kerja}

Hasil analisis menunjukkan bahwa variabel Insentif berpengaruh signifikan terhadap Prestasi kerja. Berdasarkan pengujian tersebut maka dapat disimpulkan bahwa hipotesis $\left(\mathrm{H}_{1}\right)$ yang menyatakan bahwa variabel Insentif berpengaruh secara parsial terhadap Prestasi kerja ASN di BAPPEDA Kabupaten Situbondo adalah diterima. Dan hipotesis $\left(\mathrm{H}_{3}\right)$ yang menyatakan variabel Insentif berpengaruh secara dominan terhadap Prestasi kerja ASN di BAPPEDA Kabupaten Situbondo dapat diterima. Hasil penelitian ini menunjukkan bahwa responden yaitu ASN di BAPPEDA Kabupaten Situbondo akan meningkatkan prestasinya apabila ASN mendapat Insentif yang baik di perusahaan mereka.

Argumen logis dan rasional terhadap diterimanya hipotesis pertama tersebut adalah terkait dengan Insentif yang terbentuk dari perusahaan. Hasil penelitian ini sesuai dengan pernyataan Yani (2012) "Insentif yaitu penghargaan dalam bentuk uang yang diberikan oleh suatu organisasi atau perusahaan kepada karyawannya atas dasar prestasi kerja yang tinggi atau pada karyawannya yang bekerja melampaui standar yang telah ditentukan”. Insentif dapat dirumuskan sebagai balas jasa yang memadai kepada pegawai yang prestasinya melebihi standar yang telah ditetapkan. Insentif merupakan suatu faktor pendorong bagi pegawai untuk bekerja lebih baik agar kinerja pegawai dapat meningkat.

Hasil penelitian ini sejalan dengan hasil penelitian yang dilakukan oleh Oktariansyah, Benny Usman (2021) "Pengaruh Insentif terhadap Prestasi Kerja Pegawai pada Kantor Kelurahan Tanah Mas Banyuasin”. 
P-ISSN 2580 - 7781

E-ISSN 2615 - 3238

\section{Pengaruh Etos kerja Terhadap Prestasi kerja}

Hasil analisis menunjukkan bahwa Etos kerja negatif tidak berpengaruh signifikan terhadap Prestasi kerja ASN. Berdasarkan pengujian tersebut maka dapat disimpulkan bahwa hipotesis pertama $\left(\mathrm{H}_{1}\right)$ yang menyatakan ada pengaruh secara parsial antara Etos kerja terhadap Prestasi kerja di BAPPEDA Kabupaten Situbondo adalah ditolak. Sedangkan hipotesis $\left(\mathrm{H}_{2}\right)$ yang menyatakan bahwa Etos kerja berpengaruh secara simultan terhadap Prestasi kerja ASN di BAPPEDA Kabupaten Situbondo adalah diterima.

\section{KESIMPULAN}

Berdasarkan hasil penelitian, secara parsial komunikasi mempunyai pengaruh negatif signifikan terhadap prestasi kerja. insentif berpengaruh terhadap prestasi kerja dan etos kerja tidak berpengaruh signifikan terhadap prestasi kerja di BAPPEDA Kabupaten Situbondo. Sementara itu secara simultan atau uji F menunjukkan bahwa terdapat pengaruh variabel komunikasi, insentif dan etos kerja berpengaruh terhadap Prestasi kerja. Variabel insentif berpengaruh dominan terhadap prestasi kerja di BAPPEDA Kabupaten Situbondo dapat diterima.

\section{DAFTAR PUSTAKA}

Anni Karmila Nasution. 2018. "Pengaruh Komunikasi dan Persepsi Lingkungan Kerja terhadap Prestasi Kerja Karyawan pada PDAM Tirtanadi Sumatera Utara Cabang Cemara”. Skripsi. Medan: Universitas Muhammadiyah Sumatera Utara

Feriyanto, A dan Endang, S, T. 2015. Pengantar Manajemen. Jakarta: PT. Raja Grafindo Persada

Handoko, T, H. 2012. Manajemen Personalia dan Sumber Daya Manusia. Yogyakarta: BPFE.

Hasibuan, M, S, P. 2016. Manajemen Sumber Daya Manusia. Jakarta: Bumi Aksara.

Oktariansyah, Benny Usman. 2021. Pengaruh Insentif terhadap Prestasi Kerja Pegawai pada Kantor Kelurahan Tanah Mas Banyuasin. Jurnal Media Wahana Ekonomika. Fakultas Ekonomi dan Bisnis, Universitas PGRI Palembang. Volume 17 (4) : 367-382.

Sinamo, H. 2011. Etos Kerja Profesional Navigator Anda Menuju Sukses. Jakarta: PT Spirit Mahardika. 
P-ISSN 2580 - 7781

E-ISSN 2615 - 3238

Yani, M. 2012. Manajemen Sumber Daya Manusia. Jakarta: Mitra Wacana Media. 